\title{
CHANGES IN THE REPRODUCTIVE BEHAVIOR OF WOMEN IN NORTH MACEDONIA
}

DOI: http://dx.doi.org/10.18509/GBP.2020.32

UDC: 314.17-022.252-055.2(497.7)"1991/2018"

\section{Marija Ljakoska \\ Mirjanka Madjevikj \\ Biljana Apostolovska Toshevska}

Ss. Cyril and Methodius University - Skopje, Faculty of Natural Sciences and Mathematics, Institute of Geography, North Macedonia

\begin{abstract}
The issue of fertility and population reproduction has been an actual topic in North Macedonia for years now.

The reduced birth and fertility rates, the more frequent delays of giving birth later in life, extramarital births, and reduced fertility rates are the main indicators that are pointing out the changes in the reproductive behavior. Such changes are due to the changes in lifestyle and changed social norms, the changes in the economy of the country, but also because women are more educated and emancipated compared to the past, they are getting employed after completing their education, they are more independent and have the freedom to choose whether, when and how many children they will have and so on.

Using some fertility indicators, this paper shows the changes and their intensity in the period from the beginning of the nineties of the last century until the present. Some of these indicators include changes in the number of live births, the crude and specific fertility rates, the age at which women have a child (or first child), generation replacement, and more.
\end{abstract}

Keywords: fertility, fertility rates, reproduction, North Macedonia.

\section{INTRODUCTION}

In the demographic changes, which are an inevitable and integral part of human life, there are significant changes in the reproductive behavior. These changes are often accompanied by reduced and delayed births, extramarital births, reduced fertility and fertility rates.

Fertility is a complex demographic component and one of the key indicators of population dynamics since it greatly influences the natural population change. It shows the real fertility, the frequency of births in the population over a given period of time, and thus influences the dynamics of the population change. Fertility is a reflection of the population composition regarding gender and age; it's a connection to the population growth and serves as an indicator for a more detailed assessment of the contemporary situation and a forecast of potential trends [7].

Fertility has undergone major changes in values throughout history. Namely, in many papers that have focused on fertility research, the following conclusions are noteworthy: 1. The active female population, as a rule, has fewer children than the inactive; 2 . The population with a lower level of education coincides with the unwritten rule of a larger number of children; 3 . The lower economic power of the population is associated with a higher number of children. 
However, fertility is a very complex demographic process that largely depends on the individual's decision. It is very rare to find a population that has achieved fertility close to its biological minimum, and this is due to the fact that fertility is determined by various factors that influence it to be beyond the biological minimum [24]. Among the factors that have more or less influence would be those that are of biological, social, economic, cultural, psychological and other nature [18].

On the other hand, fertility is a decisive component and the most important constructive element for the social growth of the population. Thereby, it should be borne in mind that favorable and socially desirable fertility should be determined according to the objective needs and possibilities of society and social development.

North Macedonia is characterized by highly pronounced demographic heterogeneity and differences in the fertility and reproductive behavior and fertility rates. Everywhere in the world, fertility rates have been and still are linked to social and economic development, but in our country, the impact of non-economic factors such as ethnicity, religion, and tradition have had a strong impact on the reproductive behavior of the population. However, the emphasized differences in the degree of fertility, depending on the level of education, economic activity or nationality, testify a gradual rejection of the traditional birth model [8], in the past few years.

\section{METHODOLOGY, DATA SOURCES AND LITERATURE REVIEW}

By definition, fertility is the frequency of births of a group of women in the fertile period of life. It is achieved by the physiological capacity or effective fertility expressed by the actual number of live births [13]. On the other hand, population reproduction is a process of population renewal or a process of generational replacement of the population, in which both, birth and death have their share. In a narrow sense, the reproduction of the population refers only to the female population, i.e. the part of the population which is directly involved in the process of biological reproduction [13].

Therefore, observing only the number of live births over the years is not sufficient enough to point out the changes that have occurred in fertility, fertility rates or changes in the reproductive behavior of women. Hence, this paper focuses on the scope, dynamics, and characteristics of live births, as well as on calculating some specific fertility rates as important indicators for observing the development of fertility trends over the past three decades.

The fertility rate is determined in several different ways. Often, fertility rates are determined depending on what we want to emphasize. If we analyze the connection between the number of live births and the total population, it means that we have calculated the crude fertility (birth) rate (CBR $(f))$. According to some authors, when calculating the crude fertility rate of a particular population, the female population aged 15 to 49 should actually be taken into account. In this time frame, that is, during this period of 35 years, women are considered as most capable of reproduction, that is, the most appropriate fertile age [7]. By other authors, this refers to the specific fertility rate or general fertility rate $\left(f_{e}\right)$.

An important indicator when analyzing fertility is the crude rate of total fertility which shows the number of live births per 1,000 women and men of fertile age. It is calculated as the ratio of total live births and total female and male populations in the fertile period of life $\left(f_{v}\right)$.

Also, an important indicator is the extramarital birth rate, which is defined as the number of extramarital live births per 1,000 live births (EMBR). 
As can be observed, the most commonly considered elements taken into consideration are the fertile period, the number of live births and female infants, as well as the number of the female population in the fertile period. These indicators point out the gross fertility rate $\left(b_{f}\right)$, or gross reproduction rate (GRR) [29]. But because every female newborn does not reach the age when she can get married, she does not get married, or for any reason cannot become a mother, the gross reproduction rate needs to be adjusted in order the results to be as close as possible to the true values. The corrected values are the net reproduction rate (NRR).

If we sum up all the specific fertility rates (referring to the specific rates for all age groups) and divide the result by 1,000, we get the Total Fertility Rate (TFR). According to the Population Reference Bureau, the Total Fertility Rate (TFR) is defined as the average number of children a woman would have if she survived all of her births or reproductive years [11]. Reproductive years refer to the age between 15 and 49 years. This rate shows the average number of children per woman. If that value is 2.1 it means that a basic population reproduction is ensured, i.e. that there is a generational replacement. This value is known as the critical value.

The analyses of the changes in the number of live births and calculations on the crude and specific rates required in this study would be unimaginable without an adequate database. Data on the number of live births and the characteristics of mothers are obtained from the regular annual publications by the State Statistical Office, Natural Population Change. Regarding the number of live births, it must be mentioned that when analyzing data on the number of live births, we came across a methodological problem. Namely, since 2004, the number of live births abroad is recorded as a separate category and thus has an impact on the total number of births.

Data on population number and the number of women of reproductive age are obtained from the census data (for the years in which censuses were conducted), while the most recent data are from the publications Estimations of the Population by Sex and Age. All these absolute and some relative data are available in the State Statistical Office database (MakStat database) [9].

So far, in the scientific and professional literature in the country, which focuses on the population; fertility and reproduction have been analyzed several times. In all cases, it is an analysis of different time periods, a different territorial scope and a different scientific approach. Part of that geographical literature includes papers by Daskalovski, about the demographic aspects of the natural population change, in a co-authorship with Madjevikj and Apostolovska Toshevska (2000) [3], and demographic transition, in a co-authorship with Madjevikj (2000) [4]; followed by papers dedicated to the population natural increase and some of its specifics, by Madjevikj (2000) [20], a paper dedicated to the analysis of the population birth rate in the Republic of Macedonia (2004) [19], another one on the characteristics of the fertility of the population in Macedonia (2007) [18], a paper about the regional differences in the natural population change, in co-authorship with Apostolovska Tosevska and Lakoska, (2016) [17], and others. One chapter dedicated to the natural population change, more precisely the number of births can be found in the university book "Socio-economic geography of the Republic of Macedonia" by Stojmilov and Apostolovska Toshevska (2016) [37]. One paper by Apostolovska Toshevska, in co-authorship with Gorin, is dedicated to the dynamics in the size and age of the female reproductive population (2016) [2], followed by the paper on the characteristics of reproductive behavior of Roma women (2018) [1]. Ljakoska is the author of a paper dedicated to births outside marriage (2019) [15], as well as a paper co- 
authored with Madjevikj and Apostolovska Tosevska on the displacement of women of reproductive age in municipalities in North Macedonia (2019) [16].

Among the other authors with a large number of scientific papers dedicated to this issue are Jovanović (models for fertility testing) (1997) [12], Risteski (about the demographic transition (1996) [26], about the demographic statistics $(2000,2014)$ [25], [24], for the reproduction models $(2005,2007))$ [28], [27], Kjurchiev, et al., for terms used in fertility and reproduction analysis (2011) [13] and others.

\section{RESULTS AND DISCUSSION}

As part of the changes taking place in the natural population change, is the continued decline in the total number of live births, expressed in absolute and relative terms, which at the state level began in the mid-1990s. This trend, with some oscillations, is still taking place nowadays. Reduced number of births also means lower fertility rates, and these values are crucial to the generational replacement. They determine the demographic situation in the country, the direction of the population's dynamics, its structure and, of course, the future demographic and overall development.

Table 1. Number of live births in the period 1991-2018 and index of change ${ }^{1}$

\begin{tabular}{rrrr}
\hline Year & Number of births & Basic index & Chain index \\
\hline $\mathbf{1 9 9 1}$ & 34,830 & 100 & - \\
\hline $\mathbf{1 9 9 4}$ & 33,487 & 96.1 & 96.1 \\
\hline $\mathbf{2 0 0 2}$ & 27,761 & 79.7 & 82.9 \\
\hline $\mathbf{2 0 0 4}$ & 23,361 & 67.1 & 84.2 \\
\hline $\mathbf{2 0 1 1}$ & 22,770 & 65.4 & 97.5 \\
\hline $\mathbf{2 0 1 5}$ & 23,075 & 66.3 & 101.3 \\
\hline $\mathbf{2 0 1 8}$ & 21,333 & 61.2 & 92.5 \\
\hline
\end{tabular}

Source: [30], [31], [32], [33], [34], [35], [36] and authors calculations

It is notable in Table 1 that in the period from 1991 to 2018 , the number of live births decreased by 13,497 , or approximately $40 \%$. The highest number of live births was recorded in 1991, at the very beginning of the period we are analyzing, while the lowest number was recorded in 2018. In the period from 1991 to 2011, the number was constantly decreasing, and then, in 2015 there was a slight, almost insignificant increase (1.3\%), and again, in 2018 the number of live births significantly decreased. In other words, the steady decline in the number of births is what characterizes the analyzed period. The reduced number of births also means a decline in the crude and specific fertility rates as well as the Total Fertility Rate.

The values of the crude and specific fertility rates, and also, the gross and net reproduction rates in this period, mark a constant decline. The only rate at which values have increased is that of births that occurred outside of marriage, or the extramarital birth rate (EMBR). The process of constant decrease of the Total Fertility Rate which is below the critical value of 2.1 since 1997, and continues to decline, indicates that it is far below the necessary level for the basic generation replacement (see Table 2). What worries most is Peter Mc Donald's saying that, in case the population reproduction falls below the

\footnotetext{
${ }^{1}$ The number of live births abroad as a separate category was first recorded in 2004. Since then, the number is constantly increasing (3,522 in 2004; 4,012 in 2011; 4,632 in 2015 and 5,019 in 2018), mainly due to the process of emigration of young people of reproductive age.
} 
"magical" level of 1.5 children per woman, it can be difficult to rehabilitate it or to note a rise of the fertility rate [39].

The birth rate below the critical value has also a major role in depopulation and emphasized population aging. The main goal of sustainable demographic development is the stationary population, the population of which the next generation will be the same size as the existing one. This level of basic generation replacement means that at the individual level, a woman in her reproductive period needs to be replaced by a female child, i.e. that the net reproduction rate should be equal to one [23]. This rate in North Macedonia has been below the critical value since 1995 .

Table 2. Crude fertility rate and some specific fertility rates

\begin{tabular}{rrrrrrrrr}
\hline Year & CBR $(\boldsymbol{f})$ & TFR & $\boldsymbol{f}_{\boldsymbol{e}}$ & EMBR & $\boldsymbol{f}_{\boldsymbol{v}}$ & $\boldsymbol{b}_{\boldsymbol{f}}$ & GRR & NRR \\
\hline $\mathbf{1 9 9 1}$ & 17.1 & - & 67.4 & 70.4 & 28.9 & 1.15 & 1.10 & - \\
\hline $\mathbf{1 9 9 4}$ & 17.2 & 2.23 & 66.7 & 85.4 & 29.0 & 1.13 & 1.08 & 1.04 \\
\hline $\mathbf{2 0 0 2}$ & 13.7 & 1.80 & 53.2 & 107.1 & 22.8 & 0.90 & 0.77 & 0.75 \\
\hline $\mathbf{2 0 0 4}$ & 11.5 & 1.52 & 44.4 & 122.7 & 18.9 & 0.75 & 0.73 & 0.71 \\
\hline $\mathbf{2 0 1 1}$ & 11.1 & 1.46 & 43.3 & 116.4 & 18.0 & 0.73 & 0.70 & 0.69 \\
\hline $\mathbf{2 0 1 5}$ & 11.1 & 1.50 & 44.6 & 109.6 & 18.4 & 0.75 & 0.72 & 0.71 \\
\hline $\mathbf{2 0 1 8}$ & 10.3 & 1.42 & 42.1 & 121.3 & 17.2 & 0.70 & 0.68 & 0.67 \\
\hline
\end{tabular}

Source: [30], [31], [32], [33], [34], [35], [36] and authors calculations

In the country, the low fertility rates are the consequence of many factors, but among the most important are family planning, getting married later in life, the more present "single life" on one hand, and a large number of people remain living with their parents on the other hand (social childhood), and also, the difficult socio-economic situation, psychological factors, etc. But the low fertility rate, which basically relies on the model of low reproduction also occurs as a result of the changes in the reproductive behavior that is followed by the desire for fewer children, and much less as a result of delaying marriage or not getting married at all [5], or as a result of the difficult situations in the society, psychological and other factors [21].

Reproductive behavior of women by age - The social and demographic development itself has brought changes in the way of thinking of modern people and changes in the population behavior, especially among the female population. Girls today are much more emancipated than in the past and are more likely to opt for higher education, which means enrolling and finishing college, but also master's and doctoral studies. The educational process is long-lasting and means that in that period it would be difficult for single girls to decide to marry, and even more difficult to become mothers. Besides, completing an education itself means looking for a suitable job or job opportunity, most often for jobs that are attractive and desirable for girls, so they often choose to pursue a career before starting a family. Education and career-building are time-consuming, so when girls start thinking about getting married or giving birth to a child it happens at a much older age compared to the past which means a shortened fertile period. Girls who marry at a younger age will most likely have their first child at a younger age and by the end of the fertile period, they will have the opportunity to have a second or even a third child. Girls who marry and give birth to a first child at older age, are much less likely to have a larger number of children, first, because they probably do not want a larger number of children, but also because their fertile period is shortened and often do not have time for a larger number of children. These changes in reproductive behavior are also related to women's occupation, working conditions and working hours, the type of settlement girls live in, the social environment, living conditions, place of birth (those who move from rural areas 
to the city are expected to have more children than those who were born and live in the city), religion, ethnicity, cultural background, socio-economic conditions, and of course, the biological potentials and the desire to extend the family tree.

The changes that have occurred in the period we are analyzing, can be observed through the changes in the age of mothers, that is, the decrease in the number of mothers with less than 20 years of age, 20 to 24 and mothers from the age group of 25 to 29 years, and the increase in the number of mothers aged between 30 and 34 and 35 to 39 years.

The number of mothers aged between 40 and 49 and those over 50 has declined, but this is probably because women had more children in the past, and it took a longer period of time to give birth to more children. That is why mothers were often older than 40 years. Today, the number of women deciding to have more children is decreasing, so the number of mothers at this age is decreasing.

However, thanks to the development of medicine and the new forms of assisted reproduction, many mothers of that age become mothers for the first time. But, new technologies cannot solve all problems and delaying births for the fourth decade of someone's life could have high demographic, social, and individual costs [39]. On the other hand, it is believed that an older mother will receive prenatal care more early, she will be breastfeeding her child as long as possible, especially in the first six months or at least one year after she gives birth [14].

Table 3. Mother's average age at birth and average age at birth of the first child

\begin{tabular}{rrr}
\hline Year & Mother's average age at birth & Mother's average age at birth of the first child \\
\hline $\mathbf{1 9 9 1}$ & 26.0 & - \\
\hline $\mathbf{1 9 9 4}$ & 25.9 & - \\
\hline $\mathbf{2 0 0 2}$ & 26.7 & 24.7 \\
\hline $\mathbf{2 0 0 4}$ & 27.0 & 25.0 \\
\hline $\mathbf{2 0 1 1}$ & 28.0 & 26.2 \\
\hline $\mathbf{2 0 1 5}$ & 28.2 & 26.8 \\
\hline $\mathbf{2 0 1 8}$ & 28.6 & 27.3 \\
\hline
\end{tabular}

Source: [30], [31], [32], [33], [34], [35], [36] and authors calculations

In terms of changes and differences in the age of mothers, the main indicator is the average age of mothers at the time they gave birth. Thus, in Table 3 we can see that the age of the mother increased by 2.6 years in the period we are analyzing, and so did the age of mothers who give birth to a child for the first time (2.6 years). In the second case, for a shorter period, i.e., from 2002 to 2018.

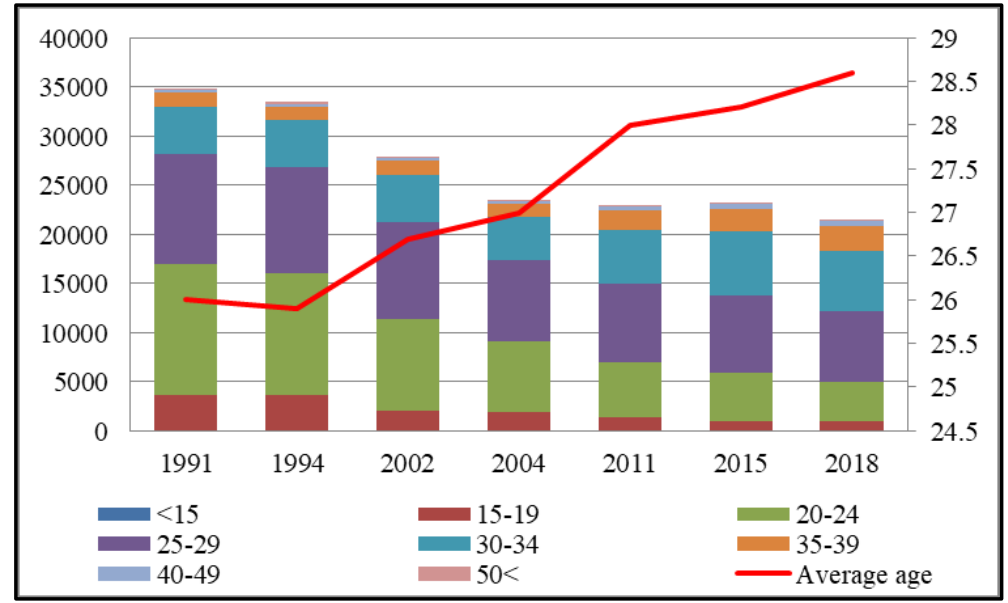

Figure 1. Live births by the age of mothers and mother's average at birth 
These data are quite worrying because increasing the female age is also associated with an increased risk of prolonged time taken to conceive [22], [38]. Also, the latest medical research shows that the reduction in fertility between the age of 28 and 33 is moderate and not significant, but after 35 , female fertility declines statistically significant, and the risk of genetic damage to the fetus increases [39]. In other words, pregnancy after the age of thirty-fifth is considered as risky and in the medical literature is known as "geriatric pregnancy" [10].

The best indicator for the changes in the age of mothers is the specific fertility rate by five-year age groups. The rates decline in almost all age groups, but this is particularly pronounced among younger mothers. Thus, the fertility rate for the age group of 15 to 19 has decreased by approximately 3 times; in the age group of 20 to 24 it has decreased by more than three times, while in the age group of 30 to 34 , the rate has increased by 0.8 times. The rate has also increased for the age group of 35 to 39 years and 40 to 44 years.

Table 4. Fertility rate by five-year age groups

\begin{tabular}{rrrrrrrrrr}
\hline \multirow{2}{*}{ Year } & \multicolumn{10}{c}{$\mathbf{5} \boldsymbol{f}_{\boldsymbol{x}}$} \\
\cline { 2 - 12 } & $\mathbf{1 5}$ & $\mathbf{1 5 - 1 9}$ & $\mathbf{2 0 - 2 4}$ & $\mathbf{2 5 - 2 9}$ & $\mathbf{3 0 - 3 4}$ & $\mathbf{3 5 - 3 9}$ & $\mathbf{4 0 - 4 4}$ & $\mathbf{4 5 - 4 9}$ & $\mathbf{5 0}<$ \\
\hline $\mathbf{1 9 9 1}$ & 0.4 & 46.3 & 179.5 & 146.5 & 59.3 & 18.4 & 3.4 & 0.3 & 0.1 \\
\hline $\mathbf{1 9 9 4}$ & 0.3 & 45.6 & 165.7 & 145.5 & 65.0 & 19.1 & 4.2 & 0.3 & 0.1 \\
\hline $\mathbf{2 0 0 2}$ & 1.1 & 23.7 & 101.6 & 112.2 & 58.2 & 17.5 & 3.7 & 0.1 & - \\
\hline $\mathbf{2 0 0 4}$ & 0.1 & 22.8 & 90.2 & 109.5 & 58.7 & 18.7 & 3.4 & 0.2 & 0.0 \\
\hline $\mathbf{2 0 1 1}$ & - & 18.1 & 71.3 & 99.9 & 72.1 & 26.6 & 3.9 & 0.2 & - \\
\hline $\mathbf{2 0 1 5}$ & - & 16.4 & 65.0 & 101.0 & 80.9 & 31.0 & 5.5 & 0.3 & - \\
\hline $\mathbf{2 0 1 8}$ & - & 15.5 & 59.1 & 95.3 & 75.6 & 33.2 & 6.0 & 0.4 & - \\
\hline
\end{tabular}

Source: [9] and authors calculations

Several reasons affect the increase in childbearing age. "As Eva Bernhardt puts it: the feeling of economic insecurity, problems with partner relations and sterility has been major factors in delaying parenting in recent decades" [39].

\section{CONCLUSION}

The complexity of historical events, social and cultural circumstances, economic, political, and other conditions have caused significant changes and have left a strong mark over the past few decades. They have played a key role in determining the direction, intensity, and duration of demographic processes. All of this accompanied by the prolonged life expectancy and reduced mortality, pushing the boundaries between the groups of young, mature, and old population, thereby changing the age of mothers.

With the economic progress, the child has lost his or her function as a factor of social security for parents at old age. Children today do not participate in the work and acquisition of material resources and as the cost of upbringing a child increases, the emotional satisfaction of individuals to decide to become parents remains the only motivation. Therefore, individuals who still want to have children find a compromise solution and decide to have fewer children, usually one [41].

Also, the age at which mothers and fathers decided to have a child is very different from that in the past, especially for women. Namely, if three decades ago women were giving birth to children at the age of 20 to 24 , or 25 to 29 , today this limit has been moved, so children are usually born at age of 30 to 34 , and even at age of 35 to 39 years. This means that women who become mothers at this age for the first time are not only exposed to the 
risk of having complicated pregnancy but also, this may be their only pregnancy given that they are at the end of their optimal reproductive period.

Although the reasons for the decline in the number of live births are not fully elucidated, some of them include aging of the fertile contingent, unemployment rate of women and their position in the family and society, insufficient financial security, small homes, etc., which results in giving up on getting married and having children [6]. On the other hand, we are witnessing the growing number of young women who want to become mothers, but not wives, and cases when the married woman does not want to give birth. In conditions of post-industrial society and modernization, the individual becomes selfsufficient and in a way selfish. He or she does not want to lose its privacy, they are unwilling to change their habits, to share their living space, or to lose economic independence [40], and therefore we can conclude that the impact of individuals' behavior is twice greater than the sum of influence caused by biological factors.

However, when it comes to biological factors, we cannot neglect the physiological birth ability of the population. It is a necessary condition for every birth, for its realization or planning. Thus, one cannot talk about childbirth planning in conditions of biological sterility that differs from conscious awareness of not having a child, where there are physiological abilities but not a desire [12].

On a national level, in conditions of low living standards, with shifted age structure and so on, it is difficult to expect a significant increase in the Total Fertility Rate. Occasional short-term improvements caused by the current population policies are not enough to seriously change this situation that can result in a reduced number of pupils in the primary schools, emphasized depopulation, the process of disappearance of the rural population, population aging, etc., [21]. Therefore, the analysis of fertility and its intensity, the changes in the number and structure of live births, as well as the changes in specific fertility rates, are necessary because of their large influence on the future demographic development.

The demographic problems we are facing affect the entire population. As the tendency to reduce the number of children becomes stronger, it is necessary to initiate certain mechanisms of action, as it should be borne in mind that children who are born today should be pupils and students tomorrow, but also, part of the labor force and pillar of society in the future. Hence, the implementation of appropriate population policy requires full co-operation between ministries and institutions in the system, co-operation between state institutions and co-operation between state and local government in order to improve the situation of the demo-reproductive processes in North Macedonia. The analysis of the contemporary demographic conditions is of particular importance to population policymakers, social scientists, demographers, and demogeographers, as well as for anyone seeking to understand society, family, marriage and reproductive behavior.

\section{REFERENCES}

[1] Apostolovska Toshevska B., Madjevikj M., Ljakoska M. \& Sokoloski P. The reproductive behavior of the female population in the only Roma governed community in Europe, Human Geographies - Journal of Studies and Research in Human Geography, Vol. 12, No. 2, pp 157-174, 2018;

[2] Apostolovska Toshevska B. \& Gorin, S. Dynamics in the scope and age of the female reproductive population in the Republic of Macedonia., Geographical Reviews, 49, pp 13-26, 2016;

[3] Daskalovski V., Madjevikj M. \& Apostolovska Tosevska B. Demographic aspects of natural population increase in the Republic of Macedonia by Ethnic Origins, International Conference 
"Changes in the 1990s and the Demographic Future of the Balkans", DEMOBALK, 1013.5.2000, Sarajevo, 2000, pp 109-112;

[4] Daskalovski V. \& Madjevikj M. The demographic transition process in the Republic of Macedonia, Proceedings of the Second Congress of Geographers, 3-5.11.2000, Ohrid, 2000, pp 1018 ;

[5] Devedjić M. The significance of marriage for the fertility level, Demography, Serbia, Vol. I, pp 73-91, 2004;

[6] Dragović A. Some factors of lower fertility in the Republic of Macedonia. IUSSP 26th International Population Population Conference, Palais des Congrès, Marrakech, 27.09.02.10.2009, Marrocco, 2009;

[7] Friganović M. Demogeography - World population, Školska knjiga, Croatia, 1978;

[8] Golubović P. \& Marković Krstić S. Models of marital and reproductive behavior of the population (using examples from Serbia, Macedonia, and Bulgaria). Proceedings of the conference, Social change, cultural and ethnic relations and euro integration processes in the Balkans, Niš, 2004, pp 269-283;

[9] http://makstat.stat.gov.mk/ (last accessed March 10, 2020)

[10] https://gyneco-blogic.com/ (last accessed March 13, 2020)

[11] https://www.prb.org/glossary/ (last accessed March 1, 2020)

[12] Jovanović A. Models for fertility testing and family planning. Annual of ISPRJ, Vol. XIX (1), pp 123-139, 1997;

[13] Kjurchiev A., Dimitriev A., Jovanović A., Janeska V. \& Lozanoska A. Demographic Terminological Glossary, Institute of Economics-Skopje, 2011;

[14] Kost K. \& Lindberg L. Pregnancy Intentions, Maternal Behaviors, and Infant Health: investigating relationships with new measures and propensity score analysis, Demography, Vol. 52, pp 83-111, 2015;

[15] Ljakoska M. Childbearing outside marriage - a case study of Macedonia, Proceedings of the 5th International Scientific Conference GEOBALCANICA 2019, 13-14 .06. 2019, Sofia, Republic of Bulgaria, 2019, pp 195-206;

[16] Ljakoska M., Madjevikj M. \& Apostolovska Toshevska B. Municipalities in North Macedonia by the scope of women in childbearing age. A Symposium dedicated to the $70^{\text {th }}$ anniversary of the Macedonian Geographical Society - New Trends in Geography, 3-4.10.2019, Ohrid, pp 191-201, 2019;

[17] Madjevikj M., Apostolovska Toshevska B. \& Ljakoska M. Regional differences in natural population growth in the Republic of Macedonia, Journal of the Geographical Institute "Jovan Cvijic", SASA, Serbia, Vol. 66, No. 3, pp 417-431, 2016.

[18] Madjevikj M. Fertility characteristics of the population in the Republic of Macedonia, Proceedings of the Scientific Meeting "Current Demographic Movements in the Republic of Macedonia in the light of 2002 Census results", MASA, Skopje, pp 455-466, 2007;

[19] Madjevikj M. Population birth rate in the Republic of Macedonia, Geographical Reviews, Vol. 38/39, pp 75-88, 2004;

[20] Madjevikj M. Some specifics of the natural population growth in the Republic of Macedonia. Geographical Reviews, Vol. 35, pp 101 -112, 2000;

[21] Marinković D. Analysis of fertile characteristics, socioeconomic status and attitudes on family planning at women who have just given birth in the Republic of Srpska, Demography, Serbia, Vol. VI, pp 65-76, 2009;

[22] Olsen J. Sub fecundity according to the age of the mother and father. Dan Med Bull 1990; 37, pp 281-282; 
[23] Petrović P. Activation of Local Self Governments in Applied Population Policy: The Case of Belgrade, Demographic review, Serbia, Vol. X(38), 2010;

[24] Risteski S. \& Trpkova-Nestorovska M. Demography - Methods and Analysis, Second ed., Faculty of Economics - Skopje, 2014;

[25] Risteski S. Demography statistics, Faculty of Economics, Skopje, 2000;

[26] Risteski S. The demographic transition in Macedonia. Skopje, 1996;

[27] Risteski S. The phenomenon of two population reproduction models in the Republic of Macedonia. Proceedings of the Scientific Meeting "Current Demographic Movements in the Republic of Macedonia in the light of 2002 Census results", MASA, Skopje, pp 55-70, 2007;

[28] Risteski S. The phenomenon of two population reproduction models in the Republic of Macedonia, Annual of the faculty of economics - Skopje, Vol. 40, pp 83-195. 2005.

[29] Siegel S.J. \& Swanson A.D. (Ed.). The methods and materials of demography, Second edition. San Diego: Elsevier Academic, pp 191-210; 371-406; 407-428; 429-453, 2004;

[30] SSO. Natural population change in the R.M., 1991, Skopje, 1992;

[31] SSO. Natural population change in the R.M., 1994, Skopje, 1995;

[32] SSO. Natural population change in the R.M., 2002, Skopje, 2003;

[33] SSO. Natural population change, 2004, Skopje, 2005;

[34] SSO. Natural population change, 2011, Skopje, 2012;

[35] SSO. Natural population change, 2015, Skopje, 2016;

[36] SSO. Natural population change, 2018, Skopje, 2019;

[37] Stojmilov A. \& Apostolovska Toshevska B. Socio-Economic geography of the Republic of Macedonia. Second edition, Skopje, 2016;

[38] Schmidt L., Sobotka T., Bentzen J.G. \& A. Nyboe Andersen. Demographic and medical consequences of postponement of parenthood, Human Reproduction Update, Vol.18, No.1 pp 2943, 2012;

[39] Tripković G. Motherhood - the cultural pattern of Serbs, Matica Srpska, Novi Sad, 1997;

[40] Vasić P. Non-marital fertility in central Serbia and Vojvodina since the beginning of the 1990s, Demography, Serbia, Vol. IV, pp 37-54. 2007;

[41] Vasić P. In what extent social and economic theories can explain long term decrease of fertility it Serbia? Demography, Serbia, Vol. IX, pp 237-256, 2012. 